\title{
UMA ANÁLISE SOBRE O ENDIVIDAMENTO DE CADETES DA AERONÁUTICA
}

\author{
Luciane Ferreira Alcoforado \\ Universidade Federal Fluminense \\ Departamento de Estatística/Programa de Pós Graduação em Eng. Civil \\ lucianea@id.uff.br \\ Caroline Ferreira Alcoforado \\ Academia da Força Aérea \\ Corpo de Cadetes \\ carol275@hotmail.com \\ Orlando Celso Longo \\ Universidade Federal Fluminense \\ Programa de Pós Graduação em Engenharia Civil \\ orlandolongo@gmail.com \\ Alessandra dos Santos Simão \\ Universidade Federal Fluminense \\ Programa de Pós Graduação em Engenharia Civil \\ ale.ssim@hotmail.com
}

\begin{abstract}
RESUMO
Este trabalho apresenta uma análise dos fatores que influenciam no endividamento do cadete durante o Curso de Formação de Oficiais. O endividamento é o processo de contrair ou assumir dívidas, trata-se de um saldo devedor oriundo do capital de terceiros. O objetivo desta pesquisa foi identificar os fatores que levam os cadetes ao endividamento financeiro a partir do estudo feito por Reinaldo Domingos em que se detalha os principais motivos que levam os brasileiros ao endividamento financeiro. Assim sendo, foi realizada uma pesquisa descritiva aplicada aos cadetes da Academia da Força Aérea Brasileira de 2018, com exceção dos cadetes aviadores do $2^{\circ}$ esquadrão e do $4^{\circ}$ esquadrão, os quais recebem uma remuneração diferente dos demais. As respostas do questionário indicaram que quase a metade dos cadetes estão endividados e que uma boa parcela dos cadetes não possui consciência deste fato. Os fatores relacionados ao planejamento financeiro apontaram que a grande maioria não o fazem e praticamente metade tem seu orçamento mensal prejudicado devido a necessidade de status social. Foi feita uma modelagem dos dados por meio do método de regressão logística, e a partir disso, observou-se que os principais fatores os quais levam o cadete ao endividamento são relacionados ao crédito fácil, parcelamentos e necessidade de status social. Concluiu-se sobre a importância de aulas práticas de educação financeira com a finalidade de aumentar a consciência dos cadetes para uma vida financeira mais estável e organizada.
\end{abstract}

Palavra-chave: Endividamento; Gestão Financeira; Fatores de endividamento; Regressão Logística. 


\begin{abstract}
This paper presents an analysis of the factors that influence cadet indebtedness during the Officer Training Course. Debt is the process of contracting or assuming debt, it is a debit balance arising from the capital of third parties. The objective of this research was to identify the factors that lead the cadets to financial indebtedness from the study by Reinaldo Domingos which details the main reasons that lead Brazilians to financial indebtedness. Therefore, a descriptive survey was applied to the cadets of the 2018 Brazilian Air Force Academy, with the exception of aviator cadets of the 2nd squadron and the 4th squadron, which receive a different remuneration from the others. The questionnaire answers indicated that almost half of the cadets are indebted and that a good portion of the cadets are not aware of this fact. Factors related to financial planning pointed out that the vast majority do not and almost half have their monthly budget damaged due to the need for social status. Data were modeled using the logistic regression method, and from this it was observed that the main factors that lead the cadet to debt are related to easy credit, installment payments and the need for social status. It is concluded that practical financial education classes are important in order to increase cadet awareness for a more stable and organized financial life.
\end{abstract}

Keywords: Indebtedness; Financial management; Debt factors; Logistic Regression.

\title{
Como Citar:
}

ALCOFORADO, Luciane F.; Alcoforado, Caroline F, Longo, Orlando C.; Simão, Alessandra S. Uma Análise sobre Endividamento de Cadetes da Aeronáutica. In: SIMPÓSIO DE PESQUISA OPERACIONAL E LOGÍSTICA DA MARINHA, 19., 2019, Rio de Janeiro, RJ. Anais [...]. Rio de Janeiro: Centro de Análises de Sistemas Navais, 2019.

\section{INTRODUÇÃO}

O Cadete da Aeronáutica é um militar em formação para se tornar oficial na Força Aérea Brasileira, formação esta que dura um período de 4 anos em regime integral cumprido na Academia da Força Aérea (AFA). Os cadetes recebem uma remuneração mensal de R\$ 1.258,82 (ano de referência 2018) durante seu período de formação, sendo este valor diferenciado apenas para cadetes aviadores do $2^{\circ}$ ano que possuem adicional de compensação orgânica, bem como os cadetes do $4^{\circ}$ ano.

Apesar de todo o auxílio dado pela Força Aérea Brasileira (FAB), existem muitos cadetes que se encontram com dificuldades financeiras e que acabam contraindo dívidas. Muitos optam por se alimentar com meios próprios, além de gastos com lazer, para visitar suas famílias, entre outros.

Segundo Dias et al. (2014) endividamento é o processo de contrair ou assumir dívidas. Trata-se de um saldo devedor oriundo do capital de terceiros.

Para Neri (2011) o desejo de consumo costuma ser maior que a renda obtida quando o indivíduo se encontra no início de sua vida profissional e ainda não possui muita maturidade. Assim, a tendência a recorrer para recursos como empréstimos é muito maior nessa fase.

Marques (2006) afirma:

O endividamento é um fato inerente à vida em sociedade, ainda mais comum na atual sociedade de consumo. Para consumir produtos e serviços, essenciais ou não, os consumidores estão -quase todos- constantemente se endividando. (MARQUES, 2006, p. 45)

Segundo Cerbasi (2003, p. 64) “o endividamento pessoal não está diretamente ligado à renda do indivíduo, e sim à forma como ele administra as suas receitas e despesas”. 
Desse modo, para Kiyosaki e Lechter (2000), fundamentos financeiros deveriam ser ministrados desde o início da vida da pessoa nas cadeiras escolares, posto que, este será um tema presente no cotidiano de toda pessoa na sua trajetória econômica e será um dos aspectos preponderantes para aqueles que pretendem usufruir de uma saúde financeira equilibrada e tranquila.

Quando o endividamento se torna um descumprimento do compromisso assumido com outrem surge a inadimplência.

A inadimplência pode ser definida como a falta de cumprimento de uma obrigação de teor financeiro. A Serasa (Centralização de Serviços dos Bancos) afirma que o consumidor inadimplente é aquele que está com uma dívida em aberto.

Desde muito jovens lidamos com assuntos financeiros em nosso cotidiano. Para os autores Bodie e Merton (2002, p.32) "Finanças é o estudo de como as pessoas alocam recursos escassos ao longo do tempo”.

Com o passar do tempo aprendemos o que é dívida, parcelamento, empréstimo, cheque especial, etc. Porém, dificilmente aprendemos a teoria por trás de tudo isso. No Brasil não existe um ensino teórico desse assunto nas escolas, a maioria das pessoas nunca chega a ter um estudo mais aprofundado sobre o tema.

Existem diversos fatores que levam as pessoas a gastarem mais do que recebem. Muitos indivíduos buscam explicações óbvias, como colocar a culpa no salário muito baixo ou no preço elevado das mercadorias, porém, os principais aspectos ligados ao endividamento, segundo Domingos (2016) são: falta de educação financeira, falta de planejamento, marketing e publicidade, crédito fácil, parcelamentos, falta de objetivos pessoais e necessidade de status social.

\subsection{EdUCAÇÃo FinANCEIRA}

De acordo com Kiyosaki e Lechter (2000, p.13) o sistema educacional brasileiro está formando "analfabetos financeiros, sem conhecimento de como o dinheiro funciona (...). Não estão preparados para enfrentar o mundo que os espera, um mundo que dá mais ênfase à despesa do que à poupança”.

Segundo Saito, Savoia e Petroni (2006) a educação financeira nas escolas é incentivada pela OCDE (Organização para Cooperação e Desenvolvimento Econômico), que afirma que a educação financeira deve começar na escola, pois é importante que as pessoas se insiram no processo o quanto antes, porém não existe a obrigatoriedade de ensinar finanças no sistema de ensino brasileiro.

Lizote, Simas e Lana (2012) acreditam que a educação financeira é essencial para capacitar o indivíduo para controlar suas receitas e despesas de forma coerente, tomando as decisões corretas tanto para o presente, quanto para o futuro. Ainda, Hanna, Hill e Perdue (2010) comentam sobre a falta de estudo de finanças nas universidades e ressaltam a sua importância, pois os alunos que entram na universidade normalmente permanecem com o mesmo nível de conhecimentos financeiros até o final da sua formação, devido a não educação financeira pessoal destes alunos.

\subsection{Planejamento Financeiro Pessoal}

Para Gitman (2002, p. 43):

O planejamento financeiro é um aspecto importante das operações nas empresas e famílias, pois ele mapeia os caminhos para guiar, coordenar e controlar as ações das empresas e das famílias para atingir seus objetivos. (GITMAN, 2002, p. 43)

Segundo Halfeld (2006) o planejamento financeiro

Consiste em estabelecer e seguir uma estratégia para manter ou acumular bens e valores, que formarão o patrimônio pessoal e familiar, podendo essa estratégia estar voltada ao 
curto, médio ou longo prazo, buscando garantir tranquilidade econômico-financeira para o indivíduo. (HALFELD, 2006, p. 17)

\section{Cherobim e Espejo (2010) afirmam que}

O planejamento pessoal está relacionado com os objetivos que cada pessoa tem na vida, e inicia com o planejamento estratégico pessoal, em que cada pessoa define o que quer ser daqui a um ano, cinco anos, dez anos e para o resto da vida. (CHEROBIM; ESPEJO, 2010, p. 42)

Como exposto no site Guia de Bolso (2015) “o controle financeiro pessoal é imprescindível para manter uma relação saudável com o próprio dinheiro, gastando dentro das possibilidades, sem endividamentos desnecessários”. São citados alguns benefícios oferecidos pelo planejamento financeiro: ter um conhecimento real sobre a sua situação financeira, conseguir atingir mais rapidamente seus objetivos financeiros, organizar o pagamento de suas contas sem a necessidade de empréstimos, planejar a tomada de empréstimos e outros endividamentos, para que eles causem o menor impacto possível sobre sua vida, não ser pego de surpresa com alguma conta ou despesa inesperada ou não planejada.

\subsection{Marketing e Publicidade}

O consumo faz parte da sociedade capitalista em que vivemos. É necessário consumir para atender as necessidades básicas de uma pessoa, mas também para manter o seu status social.

Bauman (2008) define o ato de consumir:

Consumir, portanto, significa investir na afiliação social de si próprio, o que, numa sociedade de consumidores, traduz-se em "vendabilidade”: obter qualidades para as quais já existe uma demanda de mercado, ou reciclar as que já se possui, transformando-as em mercadorias para as quais a demanda pode continuar sendo criada. (BAUMAN, 2008, p. 75)

Segundo Schmidt, Andrade e Alegransi (2016)

O consumo e os padrões impostos pela sociedade, traz uma taxatividade para a adequação social. Em outras palavras, os homens que são caracterizados como não adequados a estes padrões são considerados anormais para determinada necessidade posta atualmente na sociedade. (SCHMIDT; ANDRADE; ALEGRANSI, 2016, p. 4)

Uma publicação feita por Cabral (2018) no site Mundo Educação afirma:

Para a psicanálise, o marketing interfere na diferenciação do que se deve ou não comprar, tornando assim as pessoas incessantemente descontentes buscando nas compras algo que as conforte. Essa compulsão leva as pessoas a desprezarem seus valores e sua situação fi nanceira e as mantêm em estado de fascínio e até de hipnose. (CABRAL, 2018, s/ p.)

Os autores Costa e Mendes (2012) definem que:

A publicidade é, portanto, o meio pelo qual permite o anunciante entrar na cabeça do consumidor para provar e estabelecer o posicionamento da marca transmitindo a sua mensagem e recriando e/ou despertando necessidades de consumo. (COSTA; MENDES, 2012, p. 6)

Dessa forma, é possível observar que todo indivíduo é um consumidor. Muitas vezes, as pessoas consomem produtos/serviços para manter um padrão social perante a sociedade. Assim, o marketing e a publicidade bombardeiam o consumidor para criar uma ideia de que um determinado produto/serviço é imprescindível para sua vida. Neste contexto, muitas vezes, gerando um consumo excessivo. Esse consumo excessivo faz com que o consumidor gaste o dinheiro que não possui, com um produto que não lhe é necessário, apenas por status social, o que frequentemente leva ao endividamento do indivíduo.

\subsection{CRÉDITO FÁCIL}

O mercado financeiro brasileiro oferece diversos tipos de créditos para pessoas físicas de forma rápida e a juros elevados, contribuindo para a inadimplência do cidadão. As principais modalidades, conforme citado por Vieira (2014) são: cheque especial; cartão de crédito; empréstimo pessoal; crédito estudantil; crédito consignado; crédito direto ao 
consumidor; financiamento de casas e veículos; arrendamento mercantil; consórcios; crédito rural; microcrédito; entre outros.

Segundo Franco (2007):

Nunca se ofereceu tanto dinheiro, e de forma tão fácil aos jovens. As ofertas são feitas nas ruas, nas lojas, através da televisão e até dentro das faculdades. Basta assinar para obter o financiamento do bem desejado, o cartão de crédito ou o cheque especial. Talvez não por ou tra razão o final da história para muitos é ter seu nome na lista de maus pagadores do Serasa, ficar com restrição ao crédito e iniciar a vida adulta "no vermelho", o que pode prejudicar, inclu sive, seu trânsito no mercado de trabalho. (FRANCO, 2007, p. 4)

O cheque especial é considerado uma das modalidades mais fáceis e rápidas de serem utilizadas. De acordo com o Serasa, trata-se de um empréstimo pré-aprovado pelo banco que fica disponível em sua conta para ser utilizado a qualquer instante. Porém, como o banco não pede nenhuma garantia, os juros são elevados.

O cartão de crédito oferece um limite de crédito para que o usuário adquira bens e serviços ou realize saques em dinheiro. As tarifas são baixas, desde que a conta seja paga em dia.

O crédito ou empréstimo pessoal é uma concessão de um determinado valor para um indivíduo. Este valor deverá ser quitado posteriormente em parcelas, nas quais também serão somados os juros. Normalmente é utilizado para financiar projetos e também para quitar dívidas.

O crédito estudantil é um tipo de empréstimo oferecido pelo Ministério da Educação com o objetivo de financiar os estudos no ensino superior. O pagamento da dívida é feito somente após o término do curso.

Crédito consignado trata-se de um tipo de empréstimo concedido aos funcionários de empresas conveniadas, que são descontados diretamente no contracheque do beneficiário.

Crédito direto ao consumidor (CDC) é uma concessão de crédito para um cliente de uma determinada empresa possa adquirir produtos ou serviços na própria empresa em que é oferecido o crédito.

O financiamento habitacional é um empréstimo cujo objetivo é o financiamento de um imóvel habitacional. Também pode ser utilizado para reforma, construção ou compra do mesmo.

O Financiamento de veículos tem como objetivo a aquisição de um carro novo ou usado. O limite do crédito é acordado com base no salário do contratante.

\subsection{PARCELAMENTOS}

No Brasil empresas oferecem diversas formas de parcelamento de dívida, as mais comuns são através do cartão de crédito, carnês ou cheques pré-datados.

O maior problema dos parcelamentos é que o indivíduo se compromete a realizar pagamentos com um dinheiro que ainda não possui e, quando se acumulam diversas parcelas de diferentes compras, ele não tem condições de efetuar o pagamento, gerando dívidas e até mesmo se tornando inadimplente.

Nessa modalidade um valor que seria alto fica dividido em pequenas parcelas com valores menores, fazendo com que as pessoas tenham a falsa percepção de que estão gastando pouco e sejam estimuladas a consumir cada vez mais.

\subsection{OBjetivos Pessoais}

Os Objetivos pessoais de um indivíduo estão diretamente ligados com a sua vida financeira e sua motivação para poupar. Podem ser a aquisição de bens, o sonho da casa própria, a aquisição de um carro e também pode se tratar de uma viagem dos sonhos, uma festa de casamento ou aniversário grandioso. 
A tendência das pessoas que não possuem um objetivo financeiro definido é gastar sem fazer um planejamento de reserva de dinheiro para atingir tal objetivo.

\subsection{NECESSIDADE DE STATUS SOCIAL}

Abraham Harold Maslow desenvolveu em 1943 a "Teoria da Hierarquia das Necessidades”, e com este estudo afirma que as necessidades humanas podem ser hierarquizadas, conforme seu grau de importância. Elas são divididas em cinco níveis: necessidades fisiológicas, necessidades de segurança, necessidades sociais, necessidades de status ou autoestima e necessidades de autorrealização, como demonstrado na figura 1. A teoria diz que ao atender as necessidades fisiológicas, de segurança e sociais, o indivíduo procura satisfazer suas necessidades de status, conforme a hierarquia. Essa necessidade se trata da autoestima, o indivíduo busca a realização pessoal, mas também o reconhecimento, aprovação social, status e êxito.

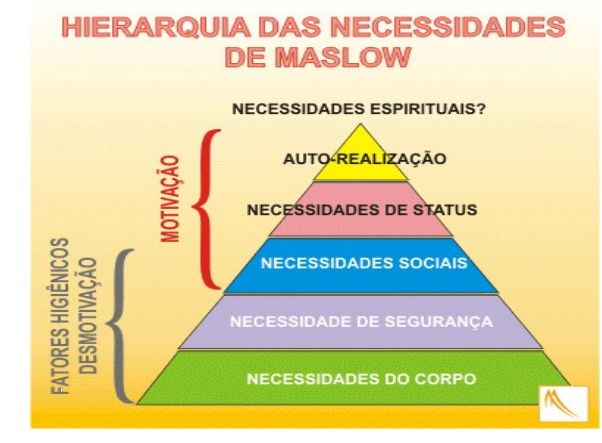

Figura 1 - Hierarquia das Necessidades de Maslow

Fonte: https://sites.google.com/site/profamarilza/home/gerenciamento-e-gestao/piramide-de-maslow (2018)

Esta pesquisa foi feita com o objetivo de esclarecer os fatores que levam os cadetes ao endividamento financeiro, quantificando o seu risco através do modelo de regressão logística. A pesquisa baseou-se num estudo feito por Reinaldo Domingos (2016) em que detalha-se os principais motivos que levam os brasileiros ao endividamento financeiro, entre eles a falta de educação financeira, de planejamento, intenso marketing e publicidade, o crédito fácil, parcelamentos, falta de sonhos e necessidade de status social.

\section{MATERIAIS E MÉTODOS}

Foi realizada uma pesquisa descritiva entre os cadetes do CCAer (Corpo de Cadetes da Aeronáutica), em Pirassununga-SP, durante o mês de agosto e setembro de 2018, através da aplicação de um questionário online (Formulário do Google) elaborado pelos autores.

$\mathrm{O}$ universo da pesquisa contemplou 339 cadetes dos $1^{\circ}, 2^{\circ}$ e $3^{\circ}$ esquadrões do CCAer, com exceção dos aviadores do segundo esquadrão e dos cadetes do $4^{\circ}$. Para seleção da amostra utilizou-se o intervalo de confiança (IC) de $90 \%$ com margem de erro de $10 \%$, obtendo-se 157 respostas de cadetes selecionados aleatoriamente em cada esquadrão, sendo 74 do $1^{\circ}$ esquadrão, 33 do $2^{\circ}$ esquadrão e 50 do $3^{\circ}$ esquadrão.

No quesito fatores de endividamento foram 17 perguntas direcionadas aos respondentes, compondo assim, o conjunto de variáveis consideradas nesta pesquisa:

1. Qual é o seu nível de estudo sobre finanças?

2. As palestras de educação financeira ministradas na AFA são úteis para a sua vida?

3. Você faz algum tipo de planejamento/controle financeiro mensal?

4. Você costuma adquirir produtos ou serviços por influência de campanhas publicitárias? Ex.: comercial na TV, vídeo de publicidade do Facebook ou YouTube, entre outros. 
5. Você costuma utilizar cartão de crédito?

6. Você utiliza o cheque especial?

7. Você já fez algum tipo de empréstimo?

8. Você já fez algum financiamento?

9. Você já fez algum consórcio?

10. Você já utilizou alguma outra modalidade de crédito além das citadas anteriormente?

11. Você costuma parcelar suas contas?

12. Você costuma parcelar gastos mensais? Ex.: compras de supermercado, combustível, etc.

13. Você faz algum tipo de investimento?

14. Você utiliza algum tipo de seguro(de carro, moto, vida, entre outros)?

15. Você possui algum objetivo financeiro? Ex.: comprar um carro ou uma casa, fazer uma viagem, festa de casamento, etc.

16. Você se sente desconfortável quando as pessoas com que convive possuem uma condição financeira melhor que a sua?

17. Você já comprou algo que prejudicou seu orçamento mensal para melhorar seu status social?

As respostas foram categorizadas em fatores com até três níveis: 0 - Raro, 1 Moderado, 2 - Elevado. Para análise dos dados foi utilizado o método da regressão logística utilizando pacotes do programa computacional R. Utilizou-se da função read_csv2 do pacote readr para leitura dos dados armazenados em planilha contendo 157 linhas e 23 colunas, correspondendo respectivamente aos respondentes e às perguntas do questionário.

\section{RESULTADOS E DISCUSSÃO}

Dos 157 respondentes, 61,1\% se diziam não endividados, entretanto ao responderem sobre faixa de endividamento foram 52,9\% que afirmaram não possuir dívidas, o que nos mostra que cadetes com alguma faixa de dívidas não se consideram endividados.

A pesquisa revelou que aproximadamente $90 \%$ dos respondentes possuem nenhum ou pouco conhecimento sobre finanças e $81,5 \%$ dos respondentes consideram as palestras sobre finanças oferecidas na AFA como úteis em suas vidas.

Sobre realizar algum tipo de investimento, 58,6\% dos respondentes afirmaram que não realizaram nenhum investimento nos últimos 6 meses.

Para análise dos dados foi utilizado o método da regressão logística utilizando pacotes do programa computacional R, R Core Team (2018). Utilizou-se o método stepwise para a seleção das variáveis explicativas através da função stepAIC do pacote MASS. A técnica de regressão logística provê uma estimativa para a probabilidade de ocorrência de determinados eventos em face de um conjunto de variáveis explanatórias, Hair et al (2005). No caso desta pesquisa, estimou a probabilidade de um cadete ser exposto a uma situação de endividamento com base na resposta às perguntas do questionário.

A equação da regressão logística representa o logaritmo da razão de chance entre estar endividado e não estar em função das variáveis explicativas selecionadas no modelo como $x_{1}, x_{2}, \ldots, x_{n}$ e é dada por:

$$
\log \frac{P}{1-P}=\beta_{0}+\beta_{1} x_{1}+\ldots+\beta_{n} x_{n} \quad \text { Sendo, }{ }^{P}=\text { probabilidade de endividamento }
$$

\subsection{AJUSTANDO O MODELO}

Regressão logística é uma técnica de classificação utilizada para prever variáveis binárias (1 ou 0), no caso em questão prever a probabilidade de um cadete ser endividado ou não. 
A equação da regressão logística representa o logaritmo da razão de chance entre estar endividado e não estar em função das variáveis explicativas selecionadas no modelo como $x_{1}, x_{2}, \ldots, x_{n}$ e é dada por:

$\log \frac{P}{1-P}=\beta_{0}+\beta_{1} x_{1}+\ldots+\beta_{n} x_{n}$

Sendo, $P=$ probabilidade de endividamento

O modelo selecionado contém 8 variáveis dentre as 17 possíveis:

$x 5=$ utiliza cartão de crédito; $x 6=$ utiliza o cheque especial;

$x 8=$ fez algum financiamento; $x 11=$ costuma parcelar suas contas;

$x 12=$ costuma parcelar gastos mensais; $x 13=$ faz algum tipo de investimento;

$x 16=$ sente desconforto sobre sua condição financeira;

$x 17=$ prejudicou orçamento mensal para melhorar seu status social é dada por:

O resumo do modelo final pode ser visto a seguir, cuja equação de regressão logística

$$
\begin{gathered}
g(x)=-6.83+2.33 * x 5+2.64 * x 6+2.08 * x 8+1.07 * x 11+1.06 * x 12 \\
-1.07 * x 13+1.55 * x 16+1.43 * x 17 \\
\text { Sendo, } g(x)=\log \frac{P}{1-P}
\end{gathered}
$$

O modelo final permite estimar a razão de chance $\left(e^{g(x)}\right)$, isto é, a razão entre a probabilidade de um cadete estar endividado e a probabilidade de não estar endividado através da equação:

$$
\frac{P(\text { Endividado })}{P(\text { não endividado })}=e^{g(x)}
$$

Tabela 1 - Fatores que Influenciam no Endividamento do Cadete

\begin{tabular}{lccc}
\hline \multicolumn{1}{c}{ Fator } & $\begin{array}{c}\text { Probabilidade } \\
\text { endividamento }\end{array}$ & $\begin{array}{c}\text { Qu } \\
\text { antas vezes? }\end{array}$ & p-valor \\
\hline Utilizar o cheque especial & Aumenta & 14.01 & $5.173 \mathrm{e}-10$ \\
Utilizar Cartão de Crédito & Aumenta & 10.08 & $3.319 \mathrm{e}-14$ \\
& & & \\
Fazer Financiamento & Aumenta & 7.99 & 0.011911 \\
$\begin{array}{l}\text { Preocupar-se com a } \\
\text { condição financeira dos } \\
\text { outros }\end{array}$ & Aumenta & 4,72 & \\
\end{tabular}


Fazer compras pensando no status social
Aumenta

4.15

Aumenta

Diminui
Aumenta
Parcelar contas

Parcelar contas mensais

Fazer investimento
0.002799

0.008709

0.032666

Fonte: Elaborado pelos autores, 2018.

A tabela 1 foi elaborada a partir dos dados obtidos na modelagem de regressão logística. O modelo revela quantas vezes aumenta ou diminui a probabilidade de endividamento frente aos fatores apresentados:

Se usar o cheque especial possui 14 vezes mais probabilidade de ser endividado do que de não ser. de não ser.

Se usar cartão de crédito tem 10 vezes mais probabilidade de ser endividado do que

Se fizer financiamento tem 8 vezes mais probabilidade de ser endividado do que de não ser.

Se der importância à condição financeira das outras pessoas com quem convive tem 5 vezes mais probabilidade de ser endividado do que de não ser.

Se fizer compras pensando em seu status social tem 4 vezes mais probabilidade de ser endividado do que de não ser.

Se parcelar suas contas ou suas contas mensais possui 3 vezes mais probabilidade de ser endividado do que de não ser

Se fizer investimento tem 3 vezes mais probabilidade de não ser endividado do que de ser.

Dessa forma, percebe-se que fazer investimento é o fator que oferece a menor chance de um desequilíbrio financeiro. Ao invés de pagar juros, recebe juros. Mas para compor ou formar um capital para investimento há que se trabalhar com um planejamento financeiro considerando a escassez de recursos. É a única forma de receber juros.

Por outro lado, utilizar cheque especial ou cartão de crédito são os fatores que mais expõem o cadete ao risco de endividamento.

\section{CONSIDERAÇÕES FINAIS}

O cenário revelado por esta pesquisa constatou que há um expressivo quantitativo de cadetes da AFA que se encontram endividados. Deste contexto, surgiu então o questionamento sobre os fatores que levam esses cadetes a ficarem endividados.

Assim, a proposta deste trabalho foi identificar quais são esses possíveis fatores e quais ações podem ser tomadas para diminuir a chance de endividamento. Para tanto, foi utilizado como base um estudo do educador financeiro Reinaldo Domingos, em que levanta sete fatores que contribuem para que as pessoas fiquem endividadas, entre eles: falta de educação financeira e planejamento financeiro, marketing e publicidade, crédito fácil, parcelamentos, falta de objetivos pessoais e necessidade de status social. A partir destes fatores, elaborou-se um questionário que possibilitou identificar quais fatores oferecem maior ou menor risco de endividamento. 
A análise dos dados revelou que quase $40 \%$ dos cadetes admitem estarem endividados, porém, é possível observar que existe uma parcela de quase $10 \%$ dos cadetes que também são devedores e não estão conscientes disso.

Foi observado ainda que a maioria dos cadetes entrevistados gozam apenas de um conhecimento superficial sobre educação financeira. Os fatores relacionados a planejamento financeiro evidenciam que o cadete não faz ou não consegue manter um controle financeiro mensal.

A partir da modelagem dos dados através do método da regressão logística foi possível identificar quais fatores foram de fato relevantes no fato do cadete estar endividado ou não. Portanto, os cadetes que utilizam cheque especial, cartão de crédito, fazem financiamento, adquirem produtos pensando apenas no status social ou parcelam seus gastos mensais possuem uma chance muito maior de estar endividado.

Já os cadetes que fazem algum tipo de investimento possuem uma chance maior de não estarem endividados, pois, já que possuem uma reserva financeira, no caso de surgir algum gasto imprevisto em determinado mês, poderão arcar com tranquilidade sem tornar-se um devedor.

De acordo com esta pesquisa, os fatores relacionados ao crédito fácil, parcelamentos, necessidade de status social e planejamento financeiro são os que mais impactam no endividamento do cadete.

Apesar da educação financeira não ter aparecido como um fator que diferencia os cadetes endividados dos não endividados, defendemos que um conhecimento mais aprofundado sobre o assunto auxilia o cadete a empregar melhor o seu dinheiro, aprendendo diferentes estratégias de investimento e evitando tornar-se um devedor.

Nesse contexto, recomenda-se um aumento de aulas sobre educação financeira na AFA, dando ênfase na conscientização dos fatores descritos aqui anteriormente. Os cadetes devem ser conscientizados sobre a importância de fazer investimentos e ter uma reserva financeira para emergências e também dos diferentes tipos de créditos existentes no mercado e aprender a analisar as vantagens e desvantagens de cada um deles. Ademais, eles devem ser alertados sobre os perigos do parcelamento e o acúmulo de dívidas.

Sendo assim, espera-se que o presente trabalho contribua na conscientização dos cadetes sobre os fatores que os levam ao endividamento, dando a oportunidade de se precaver para não se endividarem ou de encontrarem as razões de estarem endividados.

Por fim, ressalta-se que este trabalho em nenhum momento pretendeu encerrar essa discussão, e sim, contribuir para que este tema tenha continuidade considerando o seu alcance no cotidiano de formação dos cadetes e com alcance para a sua vida profissional.

\section{REFERÊNCIAS BIBLIOGRÁFICAS}

[1] BRASIL. Comando da Aeronáutica. Ministério da Defesa. Tabela dos Soldos Dos Militares das Forças Armadas. 2018. Disponível em: <http://www2.fab.mil.br/afa/index.php/sobre-a-afa/missao-visao-evalores>. Acesso em: 24 mar. 2018.

[2] Ministério da Defesa. Comando da Aeronáutica. Academia da Força Aérea. Missão da AFA Disponível em: Acesso em 24 mar. 2018.

[3] DIAS, Suzi Elen Ferreira et al. Efeitos das Estratégias de Marketing de Compras Coletivas Sobre o Comportamento Impulsivo. Revista Brasileira de Marketing, [s.I.], v. 13, n. 03, p.138-151, 1 jun. 2014. University Nove de Julho. Disponível em: <http://www.revistabrasileiramarketing.org/ojs-2.2.4/index.php/ remark/article/view/2646/pdf_163>. Acesso em: 30 jul. 2018.

[4] NERI, Marcelo. A nova classe média: o lado brilhante da base da pirâmide. São Paulo: Saraiva, 2011.

[5] MARQUES, Cláudia Lima. Sugestões para uma lei sobre o tratamento do superendividamento de pessoas físicas em contratos de crédito ao consumo: proposições com base em pesquisa empírica de 100 casos no Rio Grande do Sul. In:Direitos do consumidor endividado: superendividamento e crédito. São Paulo: Revista dos Tribunais, 2006. 
[6] CERBASI, Gustavo. Dinheiro: os segredos de quem tem. São Paulo. Editora Gente, 2003.

[7] KIYOSAKI, Robert; LECHTER, Sharon L.. Pai Rico, Pai Pobre. [s.I.]: Elsiever, 2000.

[8] BODIE, Zvi; MERTON, Robert C.. Finanças. São Paulo: Bookman, 2002.

[9] DOMINGOS, Reinaldo. Sete motivos que levam as pessoas a gastarem mais do que ganham e se endividarem. 2016. Disponível em: <http://www.administradores.com.br/artigos/economia-e-financas/ sete-motivos-que-levam-as-pessoas-a-gastarem-mais-do-que-ganham-e-se-endividarem/97465/>. Acesso em: 05 ago. 2018.

[10] SAITO, André Taue; SAVÓIA, José Roberto Ferreira; PETRONI, Liége Mariel. A educação financeira no Brasil sob a ótica da Organização de Cooperação e de Desenvolvimento Econômico (OCDE). Anais...São Paulo: EAD/FEA/USP, 2006.

[11] LIZOTE, Suzete Antonieta; SIMAS, Jaqueline de; LANA, Jeferson. Finanças pessoais: um estudo envolvendo os alunos de Ciências Contábeis de uma Instituição de Ensino Superior de Santa Catarina. IX Simpósio de Excelência em Gestão e Tecnologia, 2012.

[12] HANNA, Michael E.; HILL, Robert R.; PERDUE, Grady. School of Study and Financial Literacy. Journal Of Economics And Economic Education Research. [s.I.], p.29-38. set. 2010. Disponível em: <http:// www.alliedacademies.org/articles/school-of-study-and-financial-literacy.pdf>. Acesso em: 07 ago. 2018.

[13] GITMAN, Lawrence J.. Princípios de Administração Financeira. 7 ed. São Paulo: Harbra, 2002.

[14] HALFELD, M.. Investimentos: como administrar melhor seu dinheiro. São Paulo: Fundamento Educacional, 2006.

[15] CHEROBIM, A. P. M. S.; ESPEJO, M. M. dos S. B. (Org.) Finanças Pessoais: Conhecer para enriquecer. São Paulo: Atlas, 2010.

[16] BAUMAN, Zygmunt. Vida para consumo: A transformação das pessoas em mercadoria. Rio de Janeiro: Zahar, 2008.

[17] SCHMIDT, Ayeza; ANDRADE, Mateus Bonfim de; ALEGRANSI, Ricardo. A Influência do Marketing nas Relações de Consumo: o superendividamento da pessoa física. 2016. Disponível em: <http://portaldeperiodicos.unibrasil.com.br/index.php/anaisevinci/article/download/882/858>. Acesso em: 13 ago. 2018.

[18] CABRAL, Gabriela. Consumismo. Disponível em: <https://mundoeducacao.bol.uol.com.br/psicologia/consumismo.htm>. Acesso em: 13 set. 2018.

[19] COSTA, Maria Ivanúcia Lopes da; MENDES, Marcília Luzia Gomes da Costa. A Publicidade como ferramenta de consumo: uma reflexão sobre a produção de necessidades. 2012. Disponível em: <http:// www.bocc.ubi.pt/pag/costa-mendes-a-publicidade-como-ferramenta-de-consumo.pdf>. Acesso em: 15 ago. 2018.

[20] VIEIRA, Joana Francisco. A Relação Entre Endividamento e Falta de Planejamento Financeiro Pessoal em Um Grupo de Acadêmicos de Sétima Fase de Uma Universidade do Município de Criciúma - SC. 2014. 51 f. Monografia (Especialização) - Curso de Administração, Universidade do Extremo Sul Catarinense, Criciúma, 2014.

[21] FRANCO, Thiago Caldas. O Jovem e o Crédito: Uma Estratégia de Endividamento Precoce? 2007. Disponível em: <http://www.puc-rio.br/pibic/relatorio_resumo2007/relatorios/dir/relatorio_thiago_franco.pdf>. Acesso em: 15 ago. 2018.

[22] MASLOW, A. Introdução à psicologia do ser. Rio de Janeiro: Eldorado,1962.

[23] R CORE TEAM. R: A language and environment for statistical computing. $R$ Foundation for Statistical Computing, Vienna, Austria. URL: https://www.R-project.org/. 2018.

[24] HAIR, J.F.JR, ANDERSON, R.E., TATHAM, R.L., BLACK W.C., Análise Multivariada de dados. 5a. ed., Porto Alegre: Bookman, 2005. 